\title{
Legalidade territorial: a Capoeira Angola na Cidade de Goiás ${ }^{1}$
}

\section{Territorial Legality: Capoeira Angola in the Cidade de Goiás}

\author{
Rosemberg Ferracini \\ rosemberggeo@yahoo.com.br \\ Universidade de São Paulo
}

\begin{abstract}
Resumo: O presente texto apresenta como o conjunto de ações ritualísticas angoleiras construiu sua territorialidade legalmente na Cidade de Goiás. Estudamos a escala do corpo como demarcação territorial do grupo na praça central Vilaboense composta por cantigas de louvação, danças, toques de instrumentos negros e mediações contra a opressão de grupos de comerciantes. A autonomia do território da roda é composta pela corporalidade do grupo, crenças fundantes da arte negra denominada capoeira Angola e pelo bispo local. Suas aparições semanais apresentaram uma identidade territorial que ultrapassou os integrantes do grupo que está relacionado com o universo múltiplo da sua religiosidade.
\end{abstract}

Palavras-chave: Territorialidade. Ritual. Capoeira Angola.

Abstract: This text presents how Angolan ritual actions have built its territoriality legally in the Cidade de Goiás. We studied the scale of the body as territorial demarcation of the group in the central square Vilaboense composed by songs of praise, dances, black instruments sounds and mediations against oppression of groups of merchants. The autonomy of the territory of the circle is composed by the corporeality of the group, foundational beliefs of the black art Capoeira Angola and by local bishop. The bishop's weekly appearances showed a territorial identity which was passed to the members of the group, something that is related to the multiple universe of their religion.

Keywords: Territoriality. Ritual. Capoeira Angola.

Resumen: El texto presenta cómo el conjunto de acciones rituales angoleiras as construyó su territorialidad en la legalidad en la ciudad de Goiás. Estudiamos la escala del cuerpo como demarcación territorial del grupo en la plaza central Vilaboense compuesta por canciones de alabanza, danzas, toques de instrumentos negros y mediaciones contra la opresión de los grupos comerciantes. La autonomía del territorio de la rueda se compone por la corporalidad del grupo, creencias de la fundación del arte negra Capoeira Angola y por el obispo local. Sus apariciones semanales mostraron una identidad territorial que superó los miembros del grupo que se relaciona con el universo múltiple de su religiosidad.

Palabras clave: Territorialidad. Ritual. Capoeira Angola.

1 Este texto é parte do terceiro capítulo da nossa dissertação de mestrado intitulada O Espetáculo na Praça na Cidade de Goiás, defendida em 2006 na Universidade Federal de Goiás. O trabalho recebeu apoio do CNPq. 


\section{INTRODUÇÃO}

No período de formação do território brasileiro, da colônia ao império, não por acaso as africanidades ${ }^{2}$ foram perseguidas. Algumas destas chegaram a ser consideradas crime, como a capoeira e o candomblé (SOARES, 1994, p. 35-73). Com as décadas de conflitos e negociações, essas práticas passaram a ser aceitas na sociedade. No período republicano, na década de 1930, especificamente, a chamada era Vargas, inicia-se o processo de "branqueamento" na capoeira. Com a ajuda de mestre Bimba, alguns instrumentos como atabaque e agogô são desvinculados de sua prática, e esta se oficializa como esporte, inserindo-se na marinha com o nome de Capoeira Regional, como explica Campos (1990, p. 46). Surge posteriormente outra linha de classificação que passa a denominá-la de angola. Dentre suas características, existe o contato com o povo de santo. Sua reafricanização passou a ser assegurada via religiosidade africana, nos ritos em forma de canto, dança, música e filosofia, como afirma Pastinha (1988).

As ações na capoeira angola confirmam aquilo que Hatzfeld já afirmava, "que as crenças explicam os ritos" (1993, p. 111), já que, para esta, a proximidade com a religiosidade negra envolve orientações consideradas sagradas. De acordo com o trabalho de campo, estamos considerando que é no interior do território da roda que se transmitem e se perpetuam a corporalidade em forma de rituais, práticas e crenças fundantes desta arte negra. Nesse intento, diria Durkheim (1996, p.19) que "só se pode definir o rito após se ter definido a crença": para a expressão negra aqui apontada em que a crença tem por base a ligação com os orixás.

Para expressar essa marca, discorremos sobre o trabalho desenvolvido pelo grupo Meninos de Angola ${ }^{3}$, que buscou construir legalmente sua territorialidade ritualística aos domingos na praça Tarso Genro, conhecida popularmente como do Coreto.

Para esse debate, utilizamos o conceito de territorialidade desenvolvido por Sack (1986), para quem a territorialidade "atravessa fronteiras, símbolos e formas diferentes de combinação direta no espaço, como a mais eficiente estratégia de força, de controle e de distribuição no espaço e no tempo" (p. 32). Compreendemos que a territorialidade implica a necessidade de constituir socialmente o uso do espaço, relacionando-o sempre com o controle do território, como já registrado por nós anteriormente (FERRACINI; MAIA, 2007). Baseados em Sack (1986), aventamos a existência de uma "lógica interna de territorialidade", que é reveladora da mudança de efeitos que constituem o domínio das razões e do uso territorial a partir da inter-relação entre os grupos. Demonstraremos que a territorialidade angoleira é constituída pelos diversos atores que dividem o mesmo espaço da praça entre população local, fiéis da igreja, turistas, comerciantes, capoeiristas, entre outros. Somado a isso, os angoleiros utilizam-se dos seus corpos para expressar elementos considerados fundamentais para essa africanidade.

2 Esse conceito encontra-se explicado e fundamentado na obra de Roger Bastide (2001). Ele buscou a compreensão desse universo nas variadas perspectivas e o entendimento epistemológico afro recriado no Brasil. Utilizaremos esse conceito no decorrer do texto para discussão da manifestação capoeira angola.

3 Fundado em 1986 por Estevan de Sá, conhecido popularmente como Mestre Chuluca. Seu trabalho possui laços territoriais com o terreiro Iê Axé Ibá Ibomim. 


\section{A CORPOREIDADE ANGOLEIRA COMO ESCALA}

O esquema representado na Figura 1 nos ajuda a discorrer sobre a construção da territorialidade angoleira na praça da Cidade de Goiás e as bases filosóficas dessa africanidade. Ações territoriais que passam pela montagem, início, meio e fim dessa linha circular de capoeira, que acontece por meio de sua performance ritualística via seus atores.

Figura 1 - Esquema do território da roda

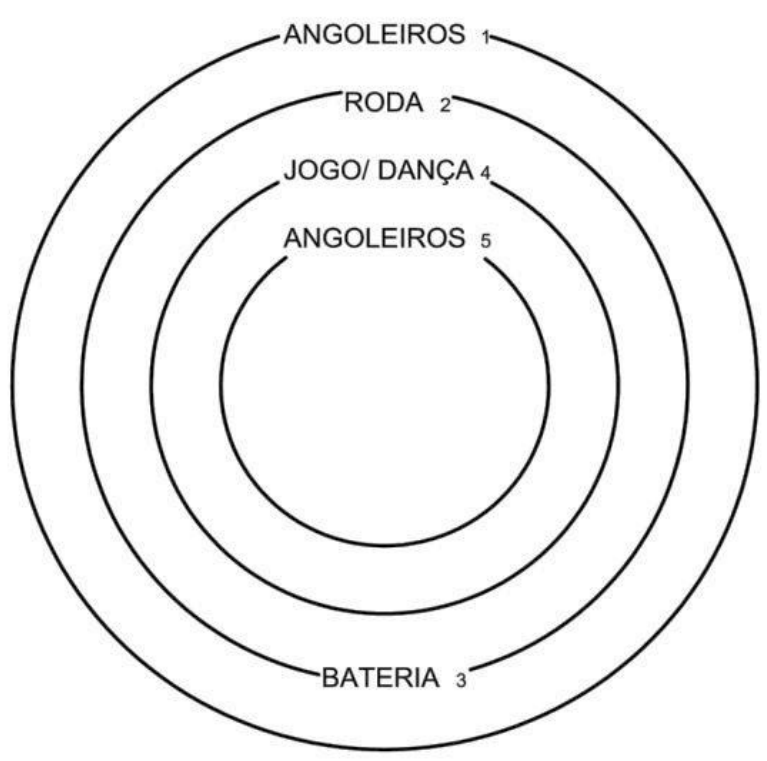

Fonte: Trabalho de Campo (FERRACINI, 2006)

1) Angoleiros - Temos os angoleiros sentados no chão e formando o círculo de divisão do mundo interno, sagrado com relação ao outro com quem se joga, brinca e dança a capoeira angola, e o mundo externo, profano e malandro. Nas aulas, aprende-se que a "roda de angola" é o palco privilegiado dos jogadores, o plano onde vão se realizar a dramaturgia e os acontecimentos do jogo/dança angoleira. Essa circunferência pode adquirir diâmetros diferenciados, sendo determinados pela quantidade de membros que estão fazendo parte do ritual, sentados no chão, demarcando assim o território alternativo e simbólico para o angoleiro.

Note-se, conforme assinala Gennep (1978), a existência de contato corporal ritualizado, o qual, de um modo geral, observa o autor, "pode consistir em contato propriamente dito (abraços aperto de mão etc)", ou pelo contato indireto, que ocorre "[...] por meio do porta-voz, pelo toque simultâneo ou sucessivo de um objeto sagrado" (p. 43). O contato entre os capoeiristas pode gerar tensões no jogo, e isso também implica práticas ritualísticas, pois, como observa Hatzfeld, "o ritual pode ser simultaneamente a consequência de uma certa instância afetiva, a resposta dada e, por conseguinte, o fim da 
tensão" (1993, p. 129). Em muitos casos, o gunga ${ }^{4}$ abaixa e finaliza o jogo/dança que se apresenta um tanto "pesada", como se quisessem pegar-se uns aos outros, e a harmonia deixasse de existir no interior da roda. Nesse sentido, o fim daquele jogo/dança em desarmonia traz consigo, de imediato, a sequência do jogo por outros participantes. Desse modo, manifestações de violência não afirmam, mas negam a fundamentação do território da roda, pois rompem com aqueles princípios históricos edificados na sua proposta, que a define como prudente, malandra e ritualística.

2) Roda - A demarcação do território representado pela "roda da vida", entre os novos acontecimentos, os fatos, as novas histórias, a circulação da energia, o transe, o axé e o êxtase, envolvidos pelo universo da música e toques instrumentais. Lembramos que nesse círculo existem os participantes sentados no chão e outros posicionando-se na bateria, postos em cadeiras ou mesmo no chão, todos cantando, tocando e observando os que "brincam" no seu interior. Nesse sentido, a roda revive no espaço a natureza "não-letrada" da transmissão de conhecimento dos povos africanos, a qual se dava sob forma oral.

O jogo/dança da capoeira angola começa ao pé do berimbau, espaço considerado sagrado para os angoleiros, que, antes de adentrarem a roda, tocam a mão no pé do berimbau e, em seguida, erguem a mão pedindo licença para a roda em sinal de consideração. Comumente, estes são mandingueiros ${ }^{5}$, em devoção à religião negra e com veneração ao ritual da roda, beijam o patuá pendurado ao pescoço, numa reverência ao seu orixá ou, como dizem, "em respeito ao santo". Usualmente, o angoleiro benze-se tocando o chão e ninguém entra na roda de angola ou sai sem antes se benzer, por fazer parte desta religiosidade. $\mathrm{O}$ angoleiro passa a compreender essa linha circular como o mundo: sabendo sair dos problemas sem se machucar ou machucar alguém. Ser angoleiro é, em princípio, construir um poder transcendente, espiritual. Tal aspecto permeia a própria entrada no rito através do "pedido de licença", ao pé do berimbau, como permissão para o início do jogo, o qual significa consideração ao próximo, independentemente de quem seja. Faz-se ainda o sinal da cruz enquanto pedindo benção.

3) Bateria - O lê é o primeiro canto, sendo uma particularidade dos ritos de angola. Podemos interpretá-lo como uma bênção em sinal ou um pedido de licença às divindades, orixás, voduns e inquices, feito logo no início da roda. Segundo os mestres, o Iê, cuja sonoridade é intensa e expressiva, é a anunciação da energia do axé. Os demais cânticos de capoeira angola são chamados ladainhas, chulas e corridos, sendo altamente significativos na vida do povo africano e, também, dessa manifestação. São compostos por

4 O berimbau gunga, assim como é denominado, possui o som mais grave, além de ditar as regras por intermédio dos sons que emite, os chamados "toques", determina o modo como se deve jogar ou dançar. É ele que dá licença para que aconteça o jogo/dança. Além do gunga, os berimbaus médio e viola estão presentes em alguns cultos do candomblé, porém em ordem diferenciada de graduação, sendo similares aos três atabaques de tamanhos diferentes, cujos nomes são rum, rumpi e lé.

5 De acordo com Reis (2003, p. 182), os amuletos com o nome de mandinga foram associados exclusivamente aos africanos, tendo sido registrados pela primeira vez em 1835, com o sentido de feitiçaria, definida como uma ação propiciatória e protetora. Sobre mandinga, Pastinha (1988, p. 6) declara "Angola, capoeira, mãe mandinga de escravo em ânsia de liberdade, seu princípio não tem método, seu fim é inconcebível ao mais sábio dos mestres". Aprendemos que o termo mandinga se refere à malandragem no jogo/dança de Capoeira Angola, às surpresas na saída da roda e nas chamadas, os avisos mandados pelos cantos e à criação de novas histórias dentro do ritual da roda. 
orações e rezas formadas por uma série de invocações curtas e respostas repetidas, relacionadas aos rituais negros. As rezas são pequenas cantigas nas quais se faz uma oração pedindo proteção no momento de iniciação da roda, que pode ser um desafio àquele com quem se joga.

Nesse conjunto, temos, juntamente com os cantos, a bateria, que é responsável pelo êxtase na movimentação dos angoleiros e envolve os que estão sentados no chão, demarcando o território da roda. Com relação ao assunto, remetemos-nos a Bastide (2001, p. 264) para exemplificar o modo como esses grupos se põem a expressar corporalmente por meio de seus ritos, quando este diz que "todo ritual é manipulação de forças sagradas, mas não é qualquer um que se pode meter a manipular." Os mesmos podem direcionar um jogo/dança mais mandingueiro ou lento. A harmonização dos instrumentos é a base de um bom rito, pois serve como alicerce do jogo/dança de angola.

Com a contextualização anterior, lembramos que um dos ritos de grande importância é a palavra cantada acompanhada de instrumentos, que dita o que se deve fazer e o que não se deve fazer. Hatzfeld comenta que "na poesia, as palavras são utilizadas naturalmente em mensagens ricas de sentido, mas também na procura de um prazer que reside no seu ritmo, na sua sonoridade, nas sutilezas do seu enquadramento" (1993, p. 113). A música muitas vezes atua como mensageira de ações, fatos, idas e vindas, para aqueles que se encontram no interior da linha circular ou para aqueles que assistem a ela.

4) Jogo/Dança - Realizam-se nessa demarcação os movimentos corporais da cabeça e dos membros. O sentir do jogo/dança de angola, desenhado pelos capoeiristas, define a configuração espacial de signos dentro dessa linha. Participar desse ato é fazer uma nova história, é saber a hora certa de entrar para não ser pego, cantar de acordo com o ritmo, estar atento para não machucar ou ser machucado, respeitar os seus limites e os do próximo. No rito dessa arte negra, é necessário saber controlar os impulsos e aprender quem é o outro. Cada qual possui seu tempo, sua relação com o espaço e sua assimilação dos ensinamentos da vida. Para o estudioso Passos Neto, "A roda é o espaço, o palco onde vai realizar o ritual; onde vai ser encenada a dramaturgia; onde vai rolar o jogo da capoeira (...) A roda como proposta de um mundo social" (1995, p. 62-65).

Nesse plano circular, também visualizamos muitos dos aspectos ligados à vida. Em análise de Passos Neto (1995), citada anteriormente, elencamos que a ideia de ritual no território da roda se aproxima constantemente com o mundo social. É a interação da vida cotidiana com a sua diversidade. Ela apresenta características de alegoria especial, entre ações não faladas e não ações, compreendendo e reverenciando o corpo em um movimento em oposição ao outro. A chamada, nesse caso, pode ser representada como uma mandinga entre um jogo e outro com um beijo no colar de proteção. No início do jogo/ dança, os atores do rito de dentro da roda enfeitam-na com desenhos que simbolizam elementos da crença e da vida.

5) Angoleiros - Os capoeiristas incorporam a responsabilidade da encenação dramática no território da roda. O jogo/dança dessa expressão é um diálogo entre quem divide a vadiagem. Se um acelera e se exalta, cabe ao outro ser mandingueiro. No jogo/ dança, pode-se parar e diminuir o seu ritmo, pois, como propõe Hatzfeld, "A ação ou 
o drama que os homens interpretam supõe que eles não estejam sós, que sejam ouvidos" (1993, p. 134). O corpo do angoleiro representa papéis e funções, tornando quase obrigatória a apresentação de uma bonita encenação. Ritualizada pela música e pelo canto, essa corporeidade impõe um modelo que é transmitido no jogo/dança, que toma forma de gingas e malandragens que fazem parte da história da capoeira angola ${ }^{6}$.

No território da roda, existe também o Iê de finalização do jogo, sendo seco e breve, que geralmente soa para sinalizar o final da roda ou marca sua parada por alguma eventualidade. As músicas na capoeira angola expressam significados múltiplos e específicos de cada momento desse rito. Muitas vezes, encontramos palavras "soltas", que servem como avisos para os angoleiros. Durkheim observa que "há palavras, frases, fórmulas, que só podem ser pronunciadas pela boca de personagens consagrados; há gestos e movimentos que não podem ser executados por todo o mundo" (1996, p. 20). É o caso do berimbau gunga, comumente na mão do mestre.

Nesse intento, as ações nesse rito de angola são atos que não podem ser quebrados: toques instrumentais, cantos de agradecimento, louvação, silêncio nas entrelinhas dos mandingueiros, encenação corporal, mandingas, deferência mútua, cumprimento de encontro e a finalização. Partimos do preceito de que as expressões ritualísticas demarcam a territorialidade angoleira do grupo estudado, dizemos que é no interior da roda de angola que ela se concretiza.

De acordo com Mauss, "Entre os ritos, há alguns que são certamente religiosos: são os ritos solenes, públicos, obrigatórios, regulares, como as festas e os sacramentos" (2003, p. 58). São essas ações que, ao serem executadas, demarcam os sacramentos da territorialidade do grupo 'Meninos de Angola' na praça, aos domingos. Os elementos ritualísticos fazem parte dos fundamentos históricos presentes no jogo da capoeira angola. Tais atividades são invioláveis. Quebrar o ritual é como faltar na ação religiosa de convicções sagradas. Nesse intento, os ritos passam a orientar os movimentos corporais entre os capoeiristas angoleiros dentro da roda de Angola. Os mesmos atos atuam como base de elemento religioso no início, no meio, e no fim das ações. Em outro momento, escreve Mauss que os "atos que não se repetem, não são mágicos (...) são eminentemente eficazes; são criadores do que fazem" (2003, p. 55-56). Para o capoeirista angoleiro, a representação de seu credo soa no sentido real de suas atividades simbólicas que são devotadas, produzidas e intensificadas pelo conjunto do grupo. Como salientado no início do tópico, entre os fundamentos da capoeira angola, estão a não violência, competição e luta física. Seu desafio é manter a tradição sendo moderna. É posicionar-se dentro e fora da roda. Ser angoleiro é ser mandingueiro.

Destarte, em nosso texto, estamos tratando a presença da corporalidade do angoleiro como escala geográfica de análise. Neste, a roda de capoeira angola exemplificada anteriormente é um fato de anos na praça aos domingos. Sua montagem semanalmente marca seu território via ritos, cantos e mandingas corporais. Não é difícil ver a movimen-

6 Alguns trabalhos artísticos demonstram essa proximidade ritualística entre a capoeira angola e o candomblé como, por exemplo, Pierre Fatumbi Verger (2002), Moacir Chaves Neto, o "Mancha", Hector Julio Páride, mais conhecido como Carybé, ilustrador e desenhista das obras de Jorge Amado. 
tação de pessoas na praça Tarso Genro, composta de $40 \mathrm{~m}^{2}$, com poucas árvores, alguns bancos e o coreto que serve como sorveteria, bar e café. É sabido e nítido por quem ali se encontra que a presença de jovens, homens e mulheres, vestidos de calça preta, camisa amarela, com berimbaus, pandeiro e reco-reco nas mãos, já demonstram que a vadiagem vai começar.

\section{A QUIZILA7 NA PRAÇA}

Aos domingos, existe uma grande circulação de pessoas na praça do coreto, seja pela tradicional missa ou como encontro ou lazer. No espaço da praça onde, aos domingos, acontece a roda, a prática já foi assimilada simbolicamente pela população local e pelos turistas. Por volta das $17 \mathrm{~h}$, é comum a chegada dos capoeiristas para a preparação da vadiagem que começa às $18 \mathrm{~h}$. O grupo Meninos de Angola, ao levar a folgança até a praça, reforça a arte negra. A bateria é montada pelo mestre, desde a distribuição dos instrumentos, até a dos elementos do grupo para o início da capoeiragem.

Entre os angoleiros, é sabido que o rito da capoeira angola na praça da Cidade de Goiás não agrada todos que a frequentam, já que esse espaço é marcado pela alteridade social. Em outro momento, registramos (FERRACINI; MAIA, 2010, p. 35-37) que tal ato se difere de outros espaços históricos onde demais expressões negras foram manifestadas e hoje não fazem parte da memória da cidade, exemplo, o bairro Bacalhau e o Museu da Boa Morte. Independentemente de ser composta por "filhos da terra", o acontecimento dominical trouxe discordâncias entre alguns dos frequentadores da praça. Estaríamos voltando ao tempo? Em uma exemplificação dessa historicidade, Karasch escreve que:

Ademais, a polícia encontrava com freqüência resistência armada quando tentava interromper uma dança. As manifestações que ela estava mais preocupada em suprimir eram as noturnas - como as religiosas - (...) os negros dançavam sem parar toda a noite de sábado [...] nos rituais de umbanda e nas noites anteriores a dias de santo [...] muitas danças eram realizadas na cidade. Três das mais significativas eram o lundu, o batuque e a capoeira. (2000, p. 328).

O fragmento anterior é apenas um dentre os diferentes contextos históricos da perseguição das africanidades no território brasileiro. Na Figura 2, a quizila na praça provoca a legalidade territorial da roda de capoeira angola.

7 Segundo Ramos (1979, p. 229), quizila é um termo que originalmente significa preceito proibido que faz parte do culto de Quimbanda em Angola, sobrevivendo no Brasil com significado de repugnância, horror, desconfiança; da expressão quigila, quizila e inquizilar. Os capoeiristas angoleiros chamaram de quizila a provocação causada pelos donos dos bares. 
Figura 2 - Legalidade territorial: o território-da-roda de Capoeira Angola na praça do coreto
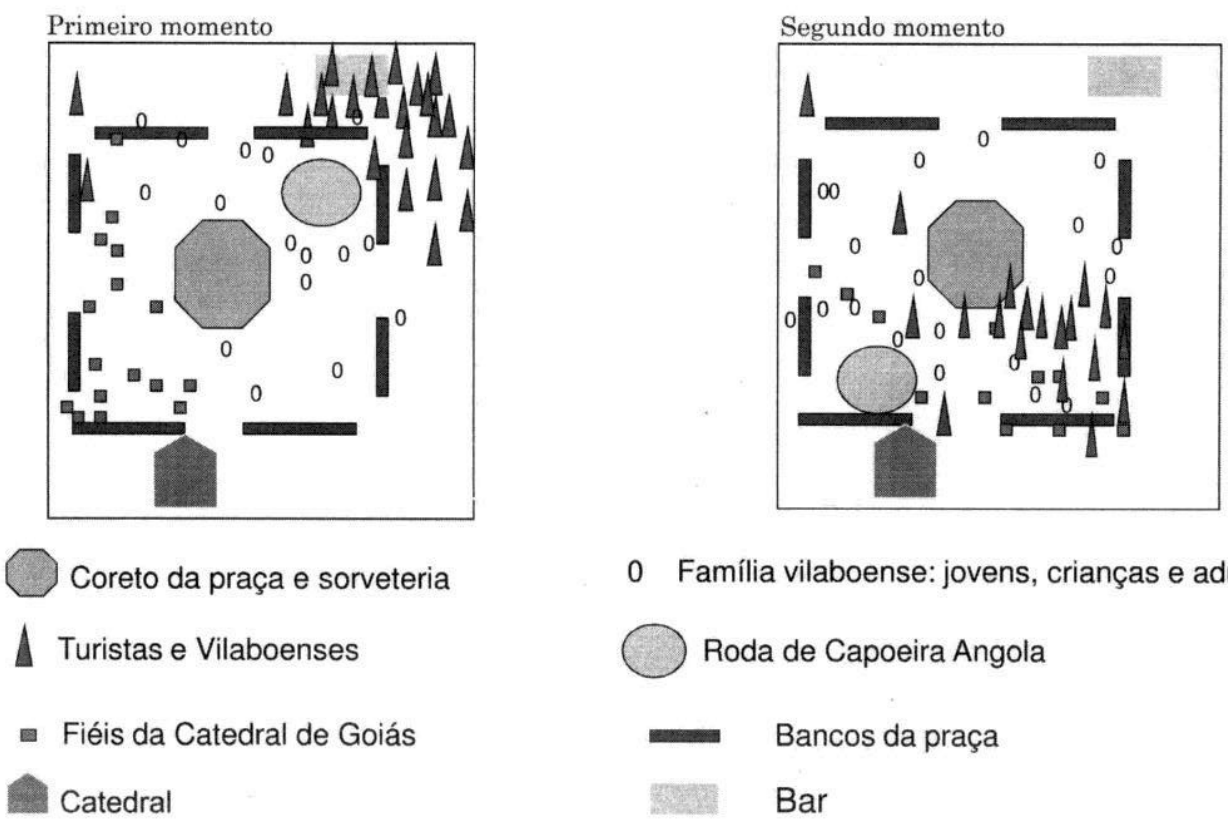

0 Família vilaboense: jovens, crianças e adultos

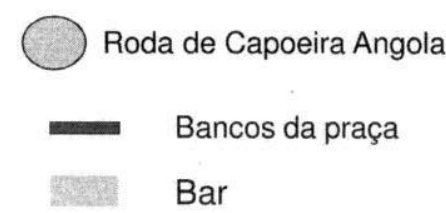

Fonte: Trabalho de Campo (FERRACINI, 2006)

Voltando ao século XXI, em determinado domingo, como de praxe, na montagem da roda, os angoleiros são repudiados por parte de alguns "donos de bares". Eles dizem que não aguentam mais as vozes do pessoal da capoeira e que isso atrapalha o trabalho do bar e a presença de seus clientes. Nesse intento, voltamos à utilização da praça enquanto espaço público, da ação, lazer e confraternização do encontro, neste caso do desencontro. Bossé afirma que "O questionamento das práticas e discursos identitários exige, portanto, que estejamos atentos aos movimentos de dominação, de controle e de exploração que ali se exprimem" (2004, p. 175). A repressão não trouxe o enfraquecimento das relações do grupo, mas multiplicou a escala de ação do que parecia ameaçado.

$\mathrm{Na}$ busca de manter a sua legitimidade na praça aos domingos, o grupo deixou de frequentá-la por alguns finais de semana, porém parte da comunidade incomodou-se com a ausência. Exemplo de inquietação foi o bispo Dom Eugênio Rixen, um dos que se descontentaram com essa ausência, e foi até a rádio local declarar-se contra a ação dos comerciantes, ficando a favor dos capoeiristas, que, por sua vez, deixaram o tempo falar. Tal processo gerou uma legitimação apriorística no que concerne ao grupo, que restituiu sua respeitabilidade e intocabilidade. A capoeira, chamada por nós de território da roda, pode continuar em frente às portas da catedral, evitando outros problemas.

Com a mudança do local, a territorialidade corporal da capoeiragem passou a se iniciar às 17 horas. Às 18 horas, quando a catedral começa a tocar os sinos para chamar os fiéis, o bispo, juntamente com os coroinhas, emitem um sinal com a cabeça para que os 'meninos e meninas de angola' parem por alguns minutos suas atividades, até o início do ritual da missa. Após a entrada dos religiosos na catedral, as portas são fechadas e a roda 
volta a entoar os cânticos e a praticar os rituais negros, como já elencados. Lembramos aqui quando em entrevista, Estevan (2005) nos disse que a roda da capoeira angolana é o limite entre o mundo e a "roda da vida". Nesse intento, a ideia do círculo nos conduz a várias experiências e a seus diversos elementos. O depoimento supracitado nos leva a pensar na ideia da "roda" em várias vivências e em seus diversos elementos e fatos. Hatzfeld (1993) afirma que os rituais ocorrem por intermédio de atividades simbólicas e que suas formas de organização possibilitam a abertura das portas para a transcendência, a comunicação com outra dimensão. Elucidamos que o ritual abre e fecha os movimentos e ações na sua roda.

Ficamos com Bossé quando escreve que a ideia de "territorialidade parece demandar a ultrapassagem desse único ponto de vista: como referência identitária, o território define tanto aquilo que lhe pertence como aquilo que lhe exclui" (2004, p. 173). Dessa forma, como já afirmado anteriormente, as vozes do grupo e o conjunto de instrumentos não são do agrado de todas as pessoas, assim como não é toda família que vai até a praça para tomar cerveja, sorvete, ou participar da missa. O território da roda ocupado pelo grupo situa-se agora diante da catedral, e não mais em frente aos bares, paradoxalmente sendo menos inconveniente à igreja que aos pequenos comerciantes. Isso gerou um processo de produção da identidade negra, que oscila entre dois movimentos: de um lado, o bispo belga, representante da Igreja Católica Apostólica Romana, que subverteu a ordem normal e adotou uma postura em relação aos angoleiros; de outro lado, os donos de bares, comerciantes, que fazem parte de um processo de engessamento, em uma posição conservadora e tradicionalista. A quizila na praça é um território de referência que um dia foi negado e hoje afirma sua corporalidade territorial por meio do mundo-da-vida-como-negro.

É agora de frente à catedral que os angoleiros potencializam e manifestam a resistência negra espacial concreta, que resgata e enaltece sua arte contra processos homogeneizantes. Dessa forma, os códigos, por meio da performance corporal dos mandingueiros, atraem ou repelem os olhos de quem por ali passa, senta, conversa, encontra, come, bebe, namora ou brinca, vendo o tempo passar ao som da vadiagem. Ser angoleiro, no sentido literal da africanidade, é respeitar não só o próximo com quem se vadia nesse rito, mas o outro alheio ao mundo da capoeiragem.

\section{IÊ - VAMOS EMBORA CAMARÁ, PELO MUNDO AFORA CAMARÁ...}

Entre ritos e mandingas da corporalidade na praça, o grupo Meninos de Angola constrói uma territorialidade única na praça na Cidade de Goiás aos domingos. Composto por crianças, adolescentes, jovens e adultos a expressão corporal dos angoleiros divulga elementos que contribuem para outra leitura desta arte no município vilaboense. Esses insistem em construir uma dinâmica contra as amarras opressivas de parte da sociedade vilaboense. Pelas crenças, cantos, manifestações ritualísticas e instrumentos, o grupo age em sinal de reverência e educação no universo dessa expressão. Nesse intento, o ritual da 
roda trabalha na união de seus alunos instigando a legitimação de um espaço, a partir de um elemento comum a eles, que é a capoeira angola enquanto arte de afirmação negra.

Não por acaso, seus ritos demarcam semanalmente o território da roda, agora com apoio do bispado. Defendemos que a construção da territorialidade do grupo Meninos de Angola ocorre, não só politicamente "por um princípio de apropriação material, mas por um princípio de identidade cultural de pertencimento" (SACK, 1986, p. 13), pela capoeiragem da vida, pelo uso comum da praça. Foi ficando ao lado dos angoleiros que Dom Eugenio Rixen posicionou-se, convencendo-nos de que o entendimento da africanidade via seus ritos, crenças e valores é realizado também por pessoas externas a ela. A quizila na praça é, ao mesmo tempo, a constituição de uma corporeidade extra daqueles que a compõem, formando uma identidade territorial que ultrapassa os integrantes do grupo.

Como registrado no início do texto, o movimento de afirmação territorial da capoeira angola enquanto expressão negra é uma construção histórica no território brasileiro. $\mathrm{O}$ exemplo retratado é somente um dos diversos fatos presentes na sua espacialidade. $\mathrm{O}$ confronto apresentado poderia não levar à legitimidade esperada. Assim, podemos dizer que a territorialidade do grupo vem sendo construída na Cidade de Goiás pela resistência daqueles que lutam pela sua efetivação e de outras territorialidades no município.

Demais africanidades nessa cidade e no Brasil vêm sendo objetos de análises geográficas, como por exemplo, o samba de roda, as casas-de-santo, o maculelê e o afoxé. Destarte, sabemos que os estudos acerca das manifestações negras na geografia brasileira ainda carecem de maiores aprofundamentos. Assim, consideramos ser importante sugerir outras questões ao tema da capoeira angola para novos debates, tais como: a identidade do angoleiro versus sua casa-de-santo; blocos carnavalescos e sambas de terreiro; uma identificação social que se manifesta em função das condições espaço-temporais como nos propõe Haesbaert (1999, p. 175) "numa relação complexa de escalas territoriais e valorações negativas e positivas"; a territorialização da capoeira angola no território brasileiro como afirmação de uma identidade negra religiosa e o debate da corporeidade como escala ligada aos grupos de angoleiros. Que Exu “abra os caminhos" para que outros se enveredem na problemática de maiores discussões acerca desse tema, pois afinal, 'o mundo dá volta camarada'.

\section{REFERÊNCIAS}

BASTIDE, Roger. O candomblé na Bahia: rito Nagô. Trad. Maria Isaura Pereira de Queiroz. 6. ed. São Paulo: Companhia das Letras, 2001.

BOSSÉ, Le Mathias. As questões de identidade em Geografia cultural. In: ROSENDHAL, Zeny; CORRÊA Roberto Lobato (Orgs.) Paisagens, textos e identidade: algumas concepções contemporâneas. Rio de Janeiro: EdUERJ, 2004. p.156-179.

CAMPOS, Hélio. Capoeira na escola. Salvador: Presscolor, 1990.

DURKHEIM, Émile. As formas elementares da vida religiosa: o sistema totêmico na Austrália. São Paulo, Martins Fontes, 1996. 
FERRACINI, Rosemberg. O espetáculo na praça: territorialidade, identidade e rituais negros na Cidade de Goiás. Dissertação de Mestrado, Universidade Federal de Goiás, 2006.

FERRACINI, Rosemberg; MAIA, Carlos Eduardo Santos. O espetáculo na praça: a roda de capoeira Angola. Espaço e Cultura, UERJ, RJ, n. 22, p. 32-42, jan./dez, 2007.

Leitura sobre o negro em Goiás a partir da capoeira Angola. Boletim Goiano de Geografia. v. 30, n. 1, p. 141-154, jan./jun. 2010.

GENNEP. Arnold Van. Os ritos de passagem: um estudo sistemático dos ritos da porta e da soleira, da hospitalidade, da adoação, gravidez e parto, nascimento, infância, puberdade, iniciação, coroação, noivado, casamento, funerais, estações, etc. Petrópolis: Vozes, 1978.

HAESBAERT, Rogério. “Identidades Territoriais". In: ROSENDHAL, Zeny; CORREAA, Roberto Lobato (Orgs.). Manifestações da cultura no espaço. Rio de Janeiro: EdUERJ, 1999. p. 169-190.

HATZFELD, Henri. As raízes da religião. Tradição, ritual e valores. Ed. Crença e Razão, 1993.

KARASCH, Mary. A vida dos escravos no Rio de Janeiro (1808-1850). São Paulo: Companhia das Letras, 2000.

MAUSS, Marcel. Sociologia e antropologia. 6.ed. São Paulo, Cosac \& Naify, 2003.

PASSOS NETO, Nestor Sezefredo dos. Ritual roda, mandinga $\mathbf{x}$ tele real. Rio de Janeiro. Dissertação de Mestrado, Escola de Comunicação da UFRJ, 1995.

PASTINHA, Vicente Ferreira. (Mestre Pastinha). Capoeira Angola. Salvador: SEC/BA, 1988.

RAMOS, Arthur. As culturas negras no Novo Mundo. 4. ed. Rio de Janeiro: Cia Editora Nacional, 1979.

SACK, Robert David. Human territorialy: its theory and history. Cambridge: University Press, 1986.

SOARES, Carlos Eugênio L. A negrada instituição: os capoeiras no Rio de Janeiro 1850-1890. Secretaria Municipal de Cultura, Departamento Geral de Documentação e Informação Cultural, Divisão de Editoração, 1994.

VERGER, Pierre Fatumbi. Orixás deuses iorubás na África no Novo Mundo. 6. ed. Salvador: Corrupio, 2002.

\section{ENTREVISTA}

ESTEVAN de Sá, "Chuluca”. 37 anos, natural da Cidade de Goiás e professor de capoeira Angola. Dados coletados no município Vilaboense no ano de 2004, 2005 e 2006.

Recebido em 14/01/2012

Aceito para publicação em 22/03/2012 